\title{
POTENSI KEPITING BAKAU Scylla serrata (Forsskal, 1775) DI KABUPATEN MERAUKE PROVINSI PAPUA
}

\author{
Siti Masiyah \\ Staf Pengajar FAPERTA UNMUS-Merauke,e-mail: S.masiyah@yahoo.com
}

\begin{abstract}
ABSTRAK
Kabupaten Merauke yang memiliki potensi yang sangat besar salah satunya adalah potensi sumberdaya alam yang dapat diperbaharui. Potensi mangrove yang masih sangat alami mendatangkan kepiting bakau semakin melimpah. Penelitian yang menggunakan data Time series dari Dinas Perikanan dan Kelautan maupun dari laporan tahunan Badan Pusat Statistik Kabupaten Merauke. Pengambilan data dari tahun 2005 - 2011. Analisis data menggunakan Metode dari Schaefer dan Fox. Dari hasil analisis didapatkan bahwa Nilai MSY menurut Schaefer dan Fox upaya penangkapan optimum masing-masing sebesar 109059.8191 ton/unit dan 72382.9154 ton/unit, tingkat eksploitasi kepiting bakau menurut Schaefer sebesar $285.6854 \%$ dengan jumlah hasil tangkapan yang diperbolehkan (JTB) sebesar 87247.8553ton/per unit. Menurut analisis dengan menggunakan Teori Fox didapatkan Tingkat eksploitasinya sebesar 430,44\% dan jumlah tangkapan yang diperbolehkan (JTB) sebesar 57906.33ton/tahun. T ingkat Tingkat eksploitasi kepiting bakau di Kabupaten Merauke mengalami kondisi tingkat over explotedatau lebih tangkap.
\end{abstract}

Kata Kunci: Kepiting bakau, Potensi, MSY, Tingkat eksploitasi

\section{PENDAHULUAN}

Kabupaten Merauke yang memiliki potensi yang sangat besar salah satunya adalah potensi sumberdaya alam yang dapat diperbaharui. Potensi mangrove yang masih sangat alami mendatangkan kepiting bakau semakin melimpah. Menurut data hasil pemetaan Pusat Survey Sumber Daya Alam Laut (PSSDAL)-Bakosurtanal dengan menganalisis data citra Landsat ETM (akumulasi data citra tahun 2006-2009, 190 scenes), mengestimasi luas mangrove di Indonesia adalah 3.244.018,46 ha (Hartini et al, 2010). Menurut (Direktur Bina Rehabilitasi Hutan dan Lahan Kementerian Kehutanan. 2009 dalam Hartini et al, 2010) luas hutan mangrove di Papua dan Papua Barat 1.634.003,454ha.

Kepiting bakau merupakan salah satu, komoditas perikanan unggulan diantaranya udang galah, kakap, kepiting, arwana dan ikan hias (Anonim, 2006). Kepiting bakau yang merupakan salah satu potensi sumberdaya perikanan unggulan di KabupatenMerauke yang banyak dimanfaatkan oleh warga sebagai mata pencaharian bagi penduduk setempat.

Terdapat berbagai macam spesies kepiting yang ada di dunia ini. Ada yang berdiam di lingkungan air tawar, bakau dan laut. Menurut Nurdin dan Armando (2010), Terdapat empat jenis kepiting bakau yang ditemui di Indonesia, yaitu kepiting bakau merah (Scylla olivacea) atau "red/orange mud $c r a b^{\prime \prime}$, kepiting bakau hijau (Scylla serrata) atau "giant mud crab" karena ukurannya yang mencapai 2-3 kg/ekor, kepiting bakau ungu (Scylla traquebarica) juga dapat mencapai ukuran besar dan kepiting bakau putih (Scylla paramamosain). Data mengenai MSY dan fMSY, tingkat Eksploitasi, JTB kepiting bakau Scylla serrata(Forsskal,1775) sangat penting dalam pengelolahan potensi kepiting bakau Scylla serrata(Forsskal,1775). Potensi kepiting bakau tersebut belum diketahui secara pasti sehingga sangat penting untuk dilakukan penelitian tersebut. 


\subsection{Tujuan Penelitian}

Tujuan penelitian dengan judul potensi kepiting bakau kepiting bakau Scylla serrata(Forsskal,1775) di Kabupaten Merauke Provinsi papua adalah untuk mengetahui nilai MSY dan fMSY, tingkat Eksploitasi, JTB kepiting bakau pada Kabupaten Merauke Provinsi Papua.

\section{METODE PENELITIAN}

\subsection{Rancangan Penelitian}

Penelitian ini dengan mengambil data time series dari dinas perikanan di Kabupaten Merauke maupun dari Badan Pusat statistic Kabupaten Merauke Provinsi Papua. Data yang diambil Mulai tahun 2007- 2011. Data yang diambil Produksi berdasarkan jenis alat (ton/tahun), produksi ikan, jumlah alat tangkap.

\subsection{Analisi Data}

1. Tingkat eksploitasi

Analisis tingkat eksploitasi kepiting bakau Scylla serrata dilakukan dengan mengumpulkan data time series berupa hasil tangkapan dan alat tangkap standart selama lima tahun dan dianalisis dengan menggunakan metode Schaefer dan Fox dalam Sparre et al, 1999 sebagai berikut:

a. Metode Schaefer

$$
\mathbf{y} / \mathbf{f}=\mathbf{a}+\mathbf{b f}
$$

Untuk menentukan potensi lestari kepiting bakau Scylla serrta adalah:

$$
\mathrm{MSY}=-\frac{a^{2}}{4 b}
$$

Dan jumlah alat tangkap optimal adalah

$$
\text { fopt }=-\frac{a}{2 b}
$$

b. Metode Fox

$$
y / f=\exp (a+b f)
$$

Untuk menentukan potensi lestari kepiting bakau adalah:

$$
\text { MSY }=\frac{-e^{a-1}}{b}
$$
adalah:

Dan jumlah alat tangkap yang optimal

$$
f_{\text {optimal }}=-\frac{1}{b}
$$

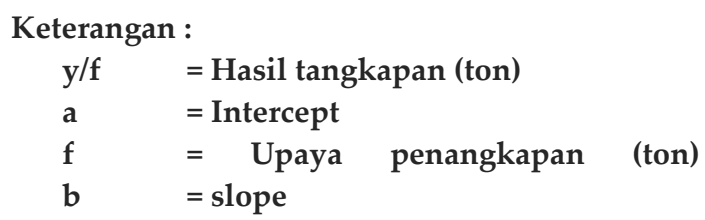

Tingkat eksploiasi dapat dihitung dengan persamaan sebagai berikut :

$$
\text { Tingkat eksp. }=\frac{\text { Produksi saat ini }}{\text { MSY }} \times 100 \% \ldots(7)
$$

Untuk mengetahui jumlah hasil tangkapan yang diperbolehkan, dapat menggunakan rumus persamaan sebagai berikut :

$$
\begin{aligned}
& \mathrm{JTB}=\mathrm{MSY} \times 80 \% \\
& >100 \% \quad \longrightarrow \quad \text { over eksploitasi } \\
& 80-100 \% \longrightarrow \text { full eksploitasi } \\
& 50-<80 \% \longrightarrow \text { medium eksploitasi } \\
& <50 \% \longrightarrow \text { Low eksploitasi }
\end{aligned}
$$

Keterangan :

Jika dihubungkan dalam tingkat pemanfaatan, maka:

1. Tingkat pemanfaatan di bawah $80 \%$ berarti kurang tangkap (under exploited)

2. Tingkat pemanfaatan berada di antara 80 $\mathbf{1 0 0 \%}$ berarti penangkapan penuh (full exploited)

3. Tingkat pemanfaatan di atas $100 \%$ berarti lebih tangkap (over exploited)

\section{HASIL DAN PEMBAHASAN}

Dalam menganalisa potensi lestari Kepiting bakau dan untuk mengetahui produksi dan upaya penangkapan atau jumlah unit alat tangkap standar (pancing) di Kabupaten Merauke dari tahun 2007-2011. data yang diambil adalah data Kabupaten. Dari model Schaefer dan Fox dengan terlebih dahulu menstandarisasikan unit alat tangkap dalam hal ini unit alat tangkap yang menjadi patokan standarisasi adalah pancing karena alat ini tergolong cukup banyak menangkap kepiting bakau dan dilokasi tersebut pemancing 
kepiting bakau lebih sering beroperasi. penangkapan kepiting bakau Scylla serrata Produksi kepiting bakau di Kabupaten (Forsskal, 1775) dengan berbagai jenis alat Merauke cenderung Berfluktuasi. Pada tahun tangkap di Kab. Merauke. Berdasarkan hasil 2007 mencapai 46816 ton dan tahun 2008-2011 mengalami kenaikan hingga mencapai 311568 ton. Produksi dan Upaya Penangkapan kepiting bakau Scylla serrata (Forsskal, 1775)dengan berbagai jenis alat tangkap di Kabupaten Merauke. Perhitungan standarisasi upaya analisa data menurut Schaefer dan Fox pada Tabel 1 Perhitungan MSY dan fMSY, tingkat Eksploitasi, JTB kepiting bakau Scylla serrata(Forsskal,1775) dengan Schaefer di Kabupaten Merauke.

Tabel 1. Perhitungan MSY dan fMSY, tingkat Eksploitasi, JTB kepiting bakau Scylla serrate (Forsskal,1775) dengan Schaefer di Kabupaten Merauke

\begin{tabular}{lrrrr}
\multicolumn{1}{c}{ Tahun } & \multicolumn{2}{c}{ Yi (ton/thn) } & fi (Unit) (X) & $\begin{array}{r}\text { Schaefer CPUE } \\
\text { (ton/Unit) (Y) }\end{array}$ \\
& 2007 & 46816 & 50525.9058 & 0.926574185 \\
& 2008 & 19331 & 20696.6213 & 0.934017187 \\
& 2009 & 37532.3 & 39582.2889 & 0.94820944 \\
& 2010 & 49095 & 45197.7607 & 1.08622638 \\
& 2011 & 311568 & 352971.8541 & 0.132633805 \\
Nilai rata-rata (x) & & & 101794.8862 & 0.8055 \\
Standar deviasi (s) & & 140862.4755 & 0.3818 \\
Intercept (a) & & & 1.0754 \\
Slope (b) & & & -0.0000027 \\
MSY & & & 109059.8191 \\
fMSY & & & 202828.8265 \\
Tingkat eksploitasi & & & \\
JTB & & & 285.6854 \\
\hline
\end{tabular}

Dari analisis didapatkan bahwa nilai MSY upaya penangkapan optimum masing-masing sebesar 109059.8191 ton/unit dan 72382.9154 ton/unit, tingkat eksploitasi kepiting bakau menurut Schaefer sebesar 285.6854\% dengan jumlah hasil tangkapan yang diperbolehkan sebesar 87247.8553ton/per unit. Hal ini mengakibatkan tingkat eksploitasi kepiting bakau di pesisir KabupatenMeraukeberada pada tingkat eksploitasi penuh dan tidak memungkinkan lagi penambahan unit alat tangkap untuk dapat memanfaatkan potensi kepiting bakau karena melebihi batas optimal unit alat tangkap.

Secara teoritis apabila potensi maksimum lestari (MSY) dibanding dengan hasil tangkapan tahunan dengan perbandingan MSY = hasil tangkapan tahunan (catch/tahun), maka tergolong kedalam tingkat (over exploited)atau lebih tangkap, jika MSY lebih besar dari produksi tahunan tergolong tingkat eksploitasi rendah dan jika MSY kurang dari produksi tahunan, maka digolongkan tingkat eksploitasi tinggi. Estimasi JTB sebesar $80 \%$ dari potensi lestari berdasarkan SK Mentan No. 995/Kpts/IK.10/9/99 tentang produksi sumberdaya ikan dan jumlah tangkapan yang diperbolehkan (JTB) di perairan Indonesia (Daduk, 2004).Model Fox, melihat hubungan antara effort dan logaritma natural dari CPUE dalam menduga MSY dan upaya penangkapan maksimum dapat dilihat pada Tabel 2. Total hasil tangkapan, upaya standar dan CPUE standar penangkapan kepiting bakau (Scylla serrata) dengan menggunakan metode Fox di pesisir Kabupaten Merauke.Perhitungan Effort Standar Penangkapan kepiting bakau Scylla serrata (Forsskal, 1775) dari setiap jenis Alat Tangkap Mulai Tahun 2007-2011 di Perairan di pesisir Kabupaten Merauke. 
Tabel 2. Perhitungan MSY dan fMSY, tingkat Eksploitasi, JTB kepiting bakau Scylla serrata(Forsskal,1775)dengan Fox diKabupaten Merauke

\begin{tabular}{lrrrr}
\hline \multicolumn{1}{c}{ Tahun } & \multicolumn{2}{c}{ Yi (ton/thn) } & fi (Unit) (X) & \multicolumn{1}{c}{$\begin{array}{r}\text { FOX Ln CPUE } \\
\text { (on/unit) (y) }\end{array}$} \\
\hline & 2007 & 46816 & 50525.9058 & -0.076261166 \\
& 2008 & 19331 & 20696.6213 & -0.06826044 \\
& 2009 & 37532.3 & 39582.2889 & -0.053179873 \\
& 2010 & 49095 & 45197.7607 & 0.082709653 \\
& 2011 & 311568 & 352971.8541 & -2.020163295 \\
Nilai rata-rata (x) & & & 101794.8862 & -0.2163 \\
Standar deviasi (s) & & 140862.4755 & 0.8929 \\
Intercept (a) & & & & 0.2134 \\
Slope (b) & & & -0.0000063 \\
MSY & & & 72382.9154 \\
Fmsy & & & 158945.9478 \\
Tingkat eksploitasi & & & 430.4441 \\
JTB & & & 57906.3323 \\
\hline
\end{tabular}

Perhitungan tingkat MSY, fmsy, tingkat Eksploitasi dan JTB di Kabupaten Merauke. Dari tabel 2 diatas dapat dilihat bahwa besarnya unit alat tangkap yang bisa memberikan produksi maksimal seimbang adalah 159845.9478 unit dengan produksi maksimal sebesar 72382.9154 ton umur relatif, sehingga dikatakan bahwa potensinya maksimumnya. Tingkat eksploitasinya sebesar $430,44 \%$ dan jumlah tangkapan yang diperbolehkan (JTB) sebesar 57906.33ton/tahun.Hal ini mengakibatkan tingkat eksploitasi kepiting bakau di Kabupaten Meraukeberada pada tingkat over exsploitasidan tidak memungkinkan lagi penambahan unit alat tangkap untuk dapat memanfaatkan potensi Kepiting bakau karena melebihi batas optimal unit alat tangkap.Perhitungan MSY dan fMSY, Tingkat Eksploitasi, JTB kepiting bakau Scylla serrata (Forsskal,1775) di Pesisir Kabupaten Merauke.

Berdasarkan hal tersebut, maka untuk menjaga agar potensi sumberdaya tetap lestari maka perlu dilakukan berbagai upaya diantaranya:

1. Menerapkan teknologi yang berwawasan lingkungan, tidak menggunakan mata jaring yang dilarang.

2. Tidak melakukan kegiatan operasi penangkapan di daerah yang dinyatakan sudah lebih tangkap, didaerah konservasi yang dilarang, di perairan yang tercemar logam berat dan di perairan yang dinyatakan terlarang.

3. Mengadakan penutupan daerah penangkapan pada suatu jenis ikan, hewan air atau biota perairan yang dilindungi mengadakan reproduksi.

4. Memberlakukan batasan waktu penangkapan sampai potensi yang ada pulih kembali.

5. Mengadakan restocking dengan cara membudidayakan atau penangkapan.

\section{Penutup}

Bedasarkan hasil penelitian, potensi kepiting bakau Scylla serrata (Forsskal, 1775) di Kabupaten Merauke Provinsi Papua dapat disimpulkan sebagai berikut:

Nilai MSY menurut Schaefer dan Fox upaya penangkapan optimum masing-masing sebesar 109059.8191 ton/unit dan 72382.9154 ton/unit, tingkat eksploitasi kepiting bakau menurut Schaefer sebesar 285.6854\% dengan jumlah hasil tangkapan yang diperbolehkan (JTB) sebesar 87247.8553ton/per unit. Menurut analisis dengan menggunakan Teori Fox didapatkan Tingkat eksploitasinya sebesar $430,44 \%$ dan jumlah tangkapan yang diperbolehkan (JTB) sebesar 57906.33ton/tahun. Tingkat Tingkat eksploitasi kepiting bakau di Kabupaten Merauke mengalami kondisi tingkat over exploted atau lebih tangkap .. 


\section{DAFTAR PUSTAKA}

Anonim, 2006. Profil investasi Kabupaten Merauke papua, Merauke.

Anonim, 2006.Profil investasi Kabupaten Merauke papua, Merauke.

2007. Laporan Tahunan. Pemerintah Kabupaten Merauke,Dinas Perikanan dan Kelautan 2008.Laporan Tahunan. Pemerintah Kabupaten Merauke,Dinas Perikanan dan Kelautan. 2009.Laporan Tahunan. Pemerintah Kabupaten Merauke, Dinas Perikanan dan kelautan. 2010. Laporan Tahunan. Pemerintah Kabupaten Merauke, Dinas Perikanan dan kelautan 2011. Laporan Tahunan. Pemerintah Kabupaten Merauke, Dinas Perikanan dan kelautan 2011.Badan Pusat statistic Kabupaten Merauke In figures. Kabupaten Merauke

Beverton,R.J.H. and S.J Holt,. 1957. On The Dynamics of exploited fish population. Fish Inverst., London 2 (19): 533p.

Gulland, J.A. 1983. Fish Stock Assesment A Manual of Basic Methocls. Willey. New York.

Hartini, S., G. B. Saputro, M. Yulianto, Suprajaka. 2010. Assessing the Used of Remotely Sensed Data for Mapping Mangroves Indonesia. Selected Topics in Power Systems and Remote Sensing. In 6th Wseas International Conference on Remote Sensing (Remote'10), Iwate Prefectural University, Japan. October 4-6, 2010; pp. 210-215.

Kasry, A. 1996. Budidaya kepiitng bakau dan biologi ringkas. Bhatara. Jakarta.87p

Nikolsky, G. V. 1963 The Ecology of Fishes. Academic Press. London

Nikolsky, G.V 1969. Theory of fish Population Dynamic, as the Biological Background of Rational Exploitation and the Manajement of Fishery resources, translated by Bradley. Oliver and Boy, 323 pp.

Nurdin dan Armando, 2010. Cara Cepat panen kepiitng soka dan Kepiting telur. Penebar swadaya. 